\title{
Ressenyes
}

\section{ETZIONI, Amitai}

\section{My Brother's Keeper. A Memoir and a Message}

Lanham, Maryland: Rowman and Littlefield Publishers, 2003

El nuevo comunitarismo sociológico es uno de los movimientos sociopolíticos más interesantes del cambio de siglo. Amitai Etzioni, antiguo presidente de la Asociación Americana de Sociología, es una de sus figuras más conocidas. Libros como The Active Society (1968), The New Golden Rule (1996) o The Third Way to a Good Society (1999), todos traducidos a nuestra lengua, dan cuenta del interés que su pensamiento ha suscitado en nuestro entorno. El interés por los trabajos de Etzioni se remonta a sus trabajos en la Universidad de California (Berkeley) en Sociología de las Organizaciones. Fue entonces cuando nació su trabajo más difundido en ese campo: Modern Organizations (1964), aún hoy citado en las referencias bibliográficas de muchos textos y programas académicos. Ahora, al filo de los setenta y cinco años, nos brinda "unas memorias y un mensaje». Se trata de un libro de 460 páginas de recuerdos ordenados casi cronológicamente, no exhaustivos pero sí esforzadamente explicativos. Relatos amenos en el que repasa su evolución, reflexiona sobre sus libros, su actividad pública... y sobre sus propias contradicciones. En el relato aparecen un buen número de personajes clave en la sociología y la ciencia política del siglo XX: M. Buber (capítulo 2), S.M. Lipset, P. Lazarsfeld y R. Merton (p. 50 y s.), D. Bell (p. 312), etc. El reconocimiento al trabajo y las palabras de afecto de Amitai Etzioni hacia Juan Linz (p. 50 y s.) durante los años de trabajo en el campus californiano de Berkeley son parte de los materiales que deben ser tenidos en cuenta para una historia de las ciencias sociales españolas en el siglo XX.

Etzioni nace en 1929 en Alemania. Sus recuerdos de infancia se enmarcan en el ambiente de persecución a los judíos. Sólo después de complicadas peripecias familiares en 1937, a través de Grecia, logra la familia volver a reunirse en una zona rural habitada por judíos en suelo palestino. Su formación escolar y su adolescencia están marcadas por la rigurosa educación en Ben Shemen (una escuela que, según afirma, «moldeó» su carácter), la vida comunitaria de las cooperativas judías agrarias y los ideales de luchar por una tierra para un pueblo desposeído. Aquellos años dan cuenta de un Etzioni joven que acaba por alistarse voluntariamente en las fuerzas especiales judías que combatieron a los países árabes a finales de los cuarenta. Los horrores de la guerra lo transfor- 
man. Acabado el conflicto, sin recursos y sin títulos que le permitan acceder a la universidad, entra en contacto con un proyecto educativo promovido por Martin Buber (p. 36 y s.). De las clases de Buber recibe "conceptos e ideas básicos» (p. 40). Después de tantos años considera que, probablemente, lo que mejor se grabó en el entonces adolescente Etzioni fue la superioridad moral del diálogo frente a las armas.

Incorporado a la Universidad Hebrea de Jerusalem y posteriormente al campus de la Universidad de California en Berkeley, dedica los años universitarios a su formación en ciencias sociales. Ya doctor, consigue un puesto como profesor en el reconocido Departamento de Sociología de la Universidad de Columbia (Nueva York). Entonces, su atención se centra en las investigaciones sobre sociología de las organizaciones. Pero su vocación no es dedicarse en exclusiva a la vida académica. Muy pronto toma conciencia de que su tarea debe estar en la universidad, pero también en el diálogo público.

\section{Intelectual público. Política y vida académica}

Prácticamente la mitad de estas memorias están dedicadas a dar cuenta de la vida de un «intelectual público» (como le gusta denominarse a sí mismo) y de lo que considera su gran proyecto académico, intelectual y político: la elaboración y difusión del nuevo comunitarismo. Desde la página 197 hasta el final de las más de cuatrocientas cincuenta páginas del texto, casi todo es comunitarismo. Y muchas de las páginas anteriores están escritas como una explicación-justificación del camino personal hacia el comunitarismo.

En algunas ocasiones da cuenta de las veces en que es criticado por no ser solamente un académico y entrar en los "poco rigurosos» modos de argumentar de la prensa o de la política. Pero a la vez comenta como, con cierta frecuencia, colegas dedicados en exclusiva a tareas académicas le han dicho expresamente: "por favor, ayúdame a entrar en contacto con el New York Times» (p. 307).

Ciertamente consigue desplegar una notable influencia política en determinados momentos de su carrera. Etzioni trabaja durante aproximadamente un año en la Casa Blanca. Su colaboración coincide con los últimos meses de la Administración Carter. Un periodo de crisis de ideas entre los más cercanos al presidente que acabará con la victoria republicana de Reagan. Ante el deterioro final de la Administración demócrata de Carter, trató, mediante el impulso de sus ideas sobre la «reindustralizacion», de aportar nuevo implulso a un equipo en decadencia (p. 137-148). En la Administración Carter también aporta su visión sobre la cuestión de los refugiados, donde tiene ocasión de concretar la relación Estado, mercado, tercer sector. No se trata de que todo lo haga el Estado (tendencia favorecida por los sistemas burocráticos del poder y por los funcionarios interesados siempre en acumular competencias); tampoco es lo mejor el sistema propuesto por los hombres de Reagan de dejar la cuestión en manos de la empresa privada. Etzioni habla de que existe un amplio sector no lucrativo de altísimo interés. Destaca ideas de Robert Putnan y Francis Fukuyama (p. 148-152).

Sobre las relaciones con la prensa, cuenta una anécdota (p. 152-153): como asesor del presidente Carter prefiere, como norma general, no atender periodistas, dejando que funcionen los cauces previstos oficialmente. Hace una excepción con un periodista que, según le informan en la propia Casa Blanca, es de confianza. Acepta tener una comida off the record sobre diversos aspectos de la actual política de la Administración Carter. Con todo, Etzioni decide ser particularmente cauteloso y no se aparta de las respuestas oficiales. Cuando ya se están levantando, el periodista pregunta por una conferen- 
cia sobre temas familiares, Etzioni dice que no es una prioridad en este momento (la conferencia, claro, no la familia). El periodista le pide permiso para, en contra de lo pactado, citarle en ese punto concreto. Etzioni explica que, quizá por debilidad, le dice que de acuerdo. A la mañana siguiente se encuentra con el siguiente titular: «Reagan dice que la Administración Carter apenas se ocupa de la familia. Etzioni piensa lo mismo».

Esta experiencia no deja el habitual resentimiento de los poderosos hacia la prensa. La visión que Etzioni tiene del periodismo se refleja mejor en las páginas que titula «Dialogues and Beyond». Los medios de comunicación son el lugar en el que se fija la agenda de temas sobre los que la sociedad dialoga en cada momento y esos diálogos son los que cambian la sociedad (cfr. p. 298-302). Por tanto, le preocupa enormemente el modo en que se plantea la tarea de "hacer noticias». Se refiere a un libro de Deborah Tannen, titulado The Argument Culture, que sostiene que el actual modo en que los periodistas confeccionan las noticias no favorece el diálogo, sino la controversia, la batalla, etc. (p. 301).

La posición dominante que supone ser alto empleado de la Casa Blanca tiene componentes éticos interesantes. Etzioni reconoce haber "traspasado la línea» en dos ocasiones (p. 154 y s.). La primera, cuando repostó en una gasolinera en la que no tenía derecho, debido a las restricciones impuestas por la autoridades públicas a ciertos vehículos. La segunda, cuando solicitó usar fondos de Defensa para uso de la Casa Blanca. En una ocasión fue plenamente consciente, en la otra apenas se dio cuenta de la posible trascendencia de la cuestión.

Muchos años más tarde, cuando Etzioni tiene notable influencia en algunos sectores cercanos a Clinton, ha tenido que zafarse de peticiones de favores diciendo que algunos «exageran mi influencia en la Casa Blanca» (p. 289).
Cuando deja la Casa Blanca renuncia a su contrato de profesor en la Universidad de Columbia y acepta una cátedra en la George Washington University. Deja Nueva York por dos motivos: Manhattan es un lugar peligroso para vivir y la familia busca un lugar apacible y, en segundo lugar, porque la capital de Estados Unidos presenta mejores oportunidades para un profesor con vocación de intelectual público.

El ambiente de los lobbies de Washington le inquieta, en la medida en que ha optado por ser un intelectual con influencia pública. Llega a comparar las relaciones entre donaciones a los políticos y los apoyos conseguidos con una casa de citas en la que se intercambian favores por dinero (p. 163). Casi todo está permitido, salvo decir «si no votas... no hay dinero".

\section{Los orígenes del nuevo comunitarismo}

Su segunda esposa, Minerva, muere en un accidente de tráfico el 20 de diciembre de 1985 (p. 167-168). Es un momento durísimo en su vida. Los días en Washington son eternos hasta que, a mediados de 1987, le ofrecen ser profesor visitante en Harvard Business School. Vende la casa, los muebles... y se traslada a Boston, donde encuentra un ambiente intelectual estimulante. Se le asigna un asistente de investigación y se encarga de un seminario para docentes.

El convencimiento del potencial del individualismo que reina en la Escuela de Negocios de Harvard le resulta muy llamativo. Y, además, se encuentra con que hablar de valores es visto como poco «liberal» (poco progresista diríamos en Europa). Un ejemplo es su participación en un seminario de profesores en el que le vienen a decir algo así como "no nos hable de valores familiares, por favor, somos progresistas» (p. 192). Pero Etzioni se plantea que esa situación es parte de la crisis del momento y la cuestión de los 
valores merece una particular atención en la economía y en las ciencias sociales en general. Un grupo de profesores e investigadores en ciencias sociales se entusiasman con esa visión, porque están hartos de los planteamientos del individualismo imperante (Amartia Sen, futuro premio Nobel, entre otros). Sus horas de trabajo en Harvard culminan con un texto largamente debatido que se publicará con el título The Moral Dimension. Toward a New Economy (p. 180-4). Los seminarios de profesores de entonces y la buena acogida del libro serán la semilla de lo que vendrá a denominarse socioeconomía. Una nueva visión de la economía que niega algunos de los principios del ultraliberalismo dominante.

Tres ideas «negativas» resumen sus planteamientos de entonces: 1) No todas las elecciones de los hombres pretenden maximizar beneficios. 2) No siempre elegimos racionalmente. 3) No elegimos solos, sino grandemente influidos por los grupos a los que pertenecemos.

¿Es éste el momento fundacional del comunitarismo etzioniano? Etzioni se refiere a una "manzana comunitarista", semejante a la manzana que hizo que Newton intuyera la ley de la gravedad (p. 194). Explica como, en un momento dado, mientras prepara una de sus clases en Harvard, se da cuenta de que los norteamericanos llevaban años ocupándose de sus derechos..., pero olvidando sus responsabilidades. Esto había provocado los excesos del individualismo. Cuando Etzioni plantea este «descubrimiento" a sus colegas de Harvard, varios le dicen que esas ideas están brillantemente expuestas en el libro coordinado por Robert Bellah titulado The Habits of the Heart. En esos días, cuando hace una reflexión sobre las ideas que tiene en la cabeza y la necesidad de difundirlas, se da cuenta de que un hombre en solitario tiene una muy limitada capacidad. Por tanto, para lanzar el movimiento comunitarista, se fija en la influencia social y política de proyectos colectivos con éxito, como el de los neoconservadores (como Lipset y Bell), un grupo de pensadores que se han constituido en «movimiento social» (p. 199-201). La difusión de esas ideas desde que empezaron a aparecer en su cabeza hasta que se convierten en una influyente perspectiva es explicada por el autor en tres fases: 1) Dar forma al mensaje. 2) Diseminarlo. 3) Transformar los hábitos del corazón.

Etzioni considera el primer paso del nuevo comunitarismo un lunch con William (Bill) Galston, al que invitó a comer, después de leer su libro Liberal Purposes. Coinciden en casi todo y Etzioni considera que ese día el comunitarismo se multiplicó. Dejó de estar solo y pasaron a ser dos.

La primera reunión del comunitarismo impulsado por Etzioni tuvo lugar en marzo de 1990 (p. 204 y s.) en George Washington University. Asisten una docena de personas venidas de diversos puntos de los Estados Unidos. Sintonizan en que en los últimos tiempos se habla mucho de derechos individuales y poco de responsabilidad para con la comunidad. Toman conciencia de ser una nueva corriente de pensamiento, distinta del autoritarismo estatista y el capitalismo imperante. Se autoproclaman responsive communitarian. Acuerdan volver a verse en torno a tres temas vinculados a las políticas de familia, salud y educación.

A mediados de octubre de 1990, se celebra la segunda reunión. Incorporó algunos nuevos participantes, entre otros, Mary Ann Glendon, invitada también personalmente por Etzioni, después de leer su libro Rights Talk.

Esas dos reuniones "fundacionales» alientan la idea de preparar un escrito seminal que llevará por título The Responsive Communiarian Platform. Etzioni trata de incluir una referencia a "valores absolutos», pero encuentra la oposición de Robert Bellah y Philip Selznick. Finalmente, no logra convencer a sus cole- 
gas y el texto en ese punto se limita a sostener que «nuestro comunitarismo no es un particularismo. Creemos que una comunidad responsable es la mejor de entre las formas de organización humana». Personalidades de relieve en la vida política y académica de los Estados Unidos unen su firma a la iniciativa etzioniana. La variedad de los firmantes sorprende. Entre los varios que enumera, aparece el apoyo crítico de la feminista Betty Friedan (p. 226), el del católico converso Richard Neuhaus, que, con el tiempo, acabaría solicitando la retirada de su firma del manifiesto (cfr. p. 227-8), etc. Al llegar a 104 firmantes, a finales de 1991, se cerró la lista. Sólo diez años más tarde, en 2001, se permitió de nuevo adherirse al texto.

En la página 239 explica el sentido por el que eligió My Brother's Keeper («El guardián de mi hermano») como título de sus memorias. Quiere ser una síntesis de sentimientos comunitaristas. Somos guardianes, no tanto en el sentido de que tenemos que denunciar lo que consideramos problemático, sino también porque tenemos la obligación de trabajar por la mejora de los demás.

\section{La difusión de las ideas etzionianas}

\section{En 1991 nace la revista The Responsive} Community: Rights and Responsabilities, de la que Etzioni es primer editor (p. 231235). En cuanto sale la revista, se enfrenta a las ingratas tareas de rechazar artículos, conseguir dinero para mantener la revista, corregir pruebas, etc. Junto a ello, destacan los aproximadamente 25 jóvenes que en los primeros diez años han pasado por la redacción, dedicando uno o dos años a ese trabajo como un primer paso para el desarrollo de una carrera académica, política o intelectual.

«Escribí The Spirit of Community entre 1990 y 1991, pero fue publicado en 1993» (p. 235). Explica dos motivos para el retraso: son necesarios cerca de nueve meses desde que el autor acaba un libro hasta que finalmente ve la luz, pero, además, el libro se enfrentó con David Groff, un activista gay que se oponía a una de las posturas expresamente expuestas en el libro. Etzioni sostenía la necesidad de que la población de riesgo se sometiera obligatoriamente a pruebas de sida, de modo que la comunidad (particularmente las parejas pasadas o futuras) conociera la posibilidad de contagio y actuara en consecuencia. Describe la contienda con el editor para publicar el texto tal como piensa que debe ser publicado. Hubiera sido interesante comparar el texto enviado a la imprenta con el que originalmente propuso a la editorial, pero Etzioni se limita a decir que logró salirse con la suya mediante algunas concesiones menores (p. 236). Un resumen de ese importante texto se puede encontrar en las páginas 236 a 240 del libro.

Etzioni explica que de los comentarios y críticas recibidos considera muy acertado el que señala que el libro, escrito sin referencias bibliográficas ni notas, no es suficiente para dar una justificación del comunitarismo con criterios académicos sólidos. Esa tarea la considera, aún hoy, pendiente de acometer.

Pienso que tiene interés para la comunidad de científicos sociales la descripción de los procedimientos empleados por el autor en su tarea de concretar y difundir sus ideas. Task Forces y Position Papers (p. 242-5) son la ocasión que utiliza el autor para describir su modo de trabajar (y de hacer trabajar a los colegas del primer comunitarismo).

El procedimiento de trabajo mediante reuniones de un día y medio podría resumirse en el siguiente itinerario: primero se convoca una reunión que comienza por la tarde y con una cena; es la ocasión de las presentaciones formales e informales, de las personas y de los temas. La mañana del día siguiente es de exposición y diálogo. Después de comer, un muy amplio periodo de descanso que 
permita intercambio de opiniones en paseos, cafés, etc. Y una reunión final en la que un ponente se encargará de dar forma a un primer borrador. En semanas sucesivas, los asistentes podrán enmendar el position paper hasta que finalmente vea la luz un documento abierto a nuevas firmas. Cuenta como ejemplo el trabajo sobre educación sexual y familia.

El comunitarismo encontró en Estados Unidos un opositor incansable en la ACLU (American Civil Liberties Union), una importante organización conservadora que vela por las libertades y los derechos de cada individuo. Creyó que las consideraciones que los planteamientos comunitaristas limitadores de las libertades individuales en aras de la comunidad eran, cuando menos, muy peligrosas (p. 249-255).

También entre las críticas que recibe el comunitarismo etzioniano están algunos sectores de la derecha religiosa norteamericana que afirman que Etzioni cae en el relativismo, no habla de Dios y es pro abortista (p. 309).

\section{El comunitarismo entra en la Casa Blanca}

Sus contactos con la Administración de Bush padre no fueron muy fructíferos. Sólo su relación con James Pinkerton, autor después de What Comes Next: The End Of Big Government and the New Paradigm, le llevaron en una ocasión a una reunión en la Casa Blanca, de la que no sale muy satisfecho (p. 258).

Cosa muy distinta son los contactos con la presidencia de Bill Clinton. El New Democratic Movement dentro del Partido Demócrata mantiene buenas relaciones con el comunitarismo. Miembros de uno y otro grupo asisten a los encuentros de los otros (p. 258-260).

De ahí que, cuando el 3 de noviembre de 1992, Bill Clinton gana las elecciones, uno de los asistentes a las reuniones fundacionales del comunitarismo etzioniano, Bill Galston, se incorpora al equipo de la Casa Blanca y sea una oportunidad para que Etzioni organice algunos eventos desde la sede presidencial. La repercusión de esos actos es muy notable, porque, como explica Etzioni, las invitaciones que uno recibe desde la Casa Blanca nunca son contestadas con un "consultaré mi agenda", sino con un "cuándo será y cuánto va a durar». Destaca dos importantes reuniones, una sobre prevención del crimen en espacios públicos (White House Conference on Public Spaces) y una segunda sobre Educación del Carácter, organizada en 1994 en colaboración con Richard Riley, entonces secretario de Educación, en la que el propio presidente Clinton hizo suyos algunos de los planteamientos comunitaristas (p. 260-268).

Etzioni dedica una veintena de páginas (272-292) a dejar clara la importante sintonía entre algunas de las ideas comunitaristas y el gobierno de Clinton. Describe la participación de Clinton (1995), Hillary (1996) y Al Gore (1997) en conferencias anuales organizadas de la Casa Blanca sobre educación del carácter, con la finalidad de orientar las políticas educativas. El escándalo Lewinski hace que no sea razonable hacer una conferencia sobre educación del carácter en la Casa Blanca y, ese año, se traslada a George Washington University, con la participación del senador Lieberman, entre otros.

Aunque no todo fue buena acogida. Por ejemplo, la fiscal general, Janet Reno, mantuvo una reunión con Etzioni en la que abordaron la cuestión de los límites del derecho a la intimidad. Reno y Etzioni no sintonizaron en absoluto.

\section{La expansión mundial del nuevo comunitarismo. Apoyos y críticas}

Etzioni distingue, en el capítulo 13 (p. 297-315) («The media and us»), tres fases en el proceso de diseminación de las 
ideas comunitaristas en los medios de comunicación: Fase I: Loud and Clear ('Alto y claro'); Fase II: Turning Critical ('Haciéndose críticos'): Fase III: Fall and Rise ('Caída y resurgimiento').

Será durante el momento en que los medios empiezan a considerar el comunitarismo etzioniano como una idea ya no muy novedosa y, por tanto, poco atractiva para los medios de comunicación, cuando Etzioni puede dedicar más tiempo a escribir. En marzo de 1999 ve la luz The Limits of Privacy, un esfuerzo por aplicar las ideas comunitaristas a una cuestión central de las relaciones entre derechos individuales y responsabilidad social (p. 313 y s.).

Llama la atención como el capítulo 14, titulado «Communitariannism goes overseas» comienza en 1995. Durante años, el comunitarismo etzioniano no se plantea seriamente salir de las fronteras norteamericanas. El autor narra una larga entrevista (en torno a una hora) con Blair en Londres (p. 323-325), en la que le expone las ideas centrales del comunitarismo. En buena medida, el resumen de esas páginas está contenido en el libro publicado en Londres cinco años después, titulado The Third Way to a Good Society (existe versión en español en Ediciones Trotta, 2001).

Etzioni describe un buen número de visitas a Alemania en las que tiene distintos encuentros con líderes políticos desde 1992 (p. 331-344).

Entre los encuentros importantes, cita el diálogo con Charles Taylor, el pensador canadiense mundialmente reconocido como uno de los padres del comunitarismo. Taylor acepta ser parte del comité editorial de The Responsive Community y actúa como presentador de Etzioni en una reunión no partidista en el Parlamento canadiense (p. 359).

En España cita expresamente la labor de asimilación y difusión de las ideas del nuevo comunitarismo por parte del sociólogo José Pérez Adán (p. 347).
Una reunión en Bruselas de comunitaristas de once países tiene como consecuencia el nacimiento del manifiesto Diversity within Unity en 2001. Un texto sobre emigración, multiculturalismo y minorías étnicas y sociales.

Las multitud de tarea desplegada en la acogida y difusión por el mundo de las ideas comunitaristas llevan al autor a exclamar como punto final de esa parte del libro, con elocuente expresividad: «Oh, Lord, the sea is so large and my oar is so small» («Dios mío, qué grande es el mar y qué pequeño mi remo») (p. 366).

\section{El influjo de Etzioni en el pensamiento social contemporáneo}

Probablemente, la frase que mejor resuma la influencia de Etzioni sea la que él mismo escribe: "cuando me presentan a alguien no es raro que me diga "Ah, usted es el gurú del comunitarismo" en lugar de aquello que solían decirme tiempo atrás «Usted debe ser el autor de Modern Organizations [...] tuve que leerlo cuando durante la carrera [...] pensé que usted había muerto hacía tiempo» (p. 368-9).

Un esfuerzo por sintetizar sus aportaciones se puede encontrar en el discurso con ocasión de su setenta cumpleaños (p. 361 y s.), en el que trata de hacer un recorrido por los diez años de comunitarismo ante 400 personas reunidas para la ocasión. En algún momento el relato puede mostrar un punto de exageración en la influencia que se atribuye el autor en ciertos cambios de tendencia de las políticas públicas. Pero el mismo Etzioni explica que estamos, sobre todo, ante una corriente que se adhiere a una gran tendencia social provocada por el cansancio ante el fuerte individualismo desatado por la era Reagan-Thatcher. No pretende el autor sostener que las ideas comunitaristas explican todo el cambio social que se da en los últimos años del siglo XX.

Para investigaciones posteriores en la obra del autor, puede ser interesante el 
número especial de 1998 de The Responsive Community sobre la obra de Etzioni (p. 379) y las diversas referencias bibliográficas, no muy extensas, en las que el autor reconoce inspiración.

Con todo, sorprende al lector familiarizado con las reflexiones comunitaristas las escasas referencias de Etzioni al pensamiento o a las obras de otros pensadores comunitaristas. Las referencias a Charles Taylor, Michael Sandel y Michael Walzer son escasas y raramente reconocen una particular influencia (cfr. por ejemplo página 206 o página 359) o lo hace tan tímidamente que apenas se explicita (cfr. p. 195). Llama la atención la ausencia de referencias al comunitarismo de autores como J. Maritain y E. Mounier, principales exponentes del comunitarismo personalista europeo de principios del siglo XX. La breve cita de Etzioni a Francia se limita a registrar la falta de acogida del nuevo comunitarismo en aquellas tierras (p. 346-7). Clásicos de la sociología como Durkheim, Tönnies, Park y Mead, son recogidos como raíz del pensamiento comunitarista, en la medida que alumbran las nuevas aportaciones de Etzioni desde su formación en los primeros años de estudio universitarios en Jerusalem (cfr. p. 195). Pero el elenco parece adolecer de cierta falta de gratitud hacia las fuentes. en un esfuerzo por subrayar la originalidad de los propios planteamientos.

El libro es un trabajo extenso, lleno de información y de condensadas reflexiones que vienen a sintetizar buena parte de la obra de uno de los sociólogos más influyentes de los últimos años. $\mathrm{Al}$ mismo tiempo, es una referencia obligada para los que vean la vida académica como necesariamente compatible con la influencia sociopolítica.

\section{José A. Ruiz San Román \\ Universidad Complutense de Madrid jars@villanueva.edu}

SPENSKY, Martine (dir.)

Citoyenneté(s) - Perspectives internationales

París: CRECM, 2003.

Desde hace algunos años, la problemática de la inmigración en España ha suscitado una reflexión que ha ido más allá de las habituales propuestas institucionales en torno a la gestión de la diversidad cultural y que no ha dudado en plantear la cuestión del estatus de los extranjeros residentes en el seno de la sociedad civil, es decir, la delimitación de sus derechos y de sus obligaciones, en tanto que ciudadanos no nacionales. Esto comprueba que el carácter permanente de la presencia entre nosotros de una población migrante, de diversos orígenes, no solamente constituye un hecho admitido, sino que se configura como objeto de estudio, y a continuación, como ámbito de debate y de reivindicaciones de derechos por parte de los interesados. Sin embargo, la perspectiva se limita mayoritariamente al ámbito español, con alguna que otra alusión puntual a la situación de otros países. El libro publicado bajo la dirección de Martine Spensky ofrece la posibilidad de realizar una reflexión más profunda y más sistemática sobre la ciudadanía a partir de un enfoque claramente comparatista cuyo objetivo principal es poner de relieve la polisemia del concepto, según el término utilizado por la editora misma en la introducción, y, por consiguiente, la variabilidad del estatus que recubre según el contexto, como el plural entre paréntesis del título sugiere. Podríamos hablar sin demasiada exageración de un concepto de geometría varia- 